\title{
O s limites da participação dos trabalhadores nos ganhos das empresas
}

\author{
FRAN CISCO PAULO CIPOLLA*
}

The limits of workers' share in profits. This article argues that workers' share in profits are actually a share in extra surplus value obtained by means of more intensified labor. Cost reductions obtained by means of more intensified lean production methods cause wages to represent a smaller fraction of the product of a working day when measured at market value. The increased market rate of surplus value is the basis for workers' shares in profits. However, as competition continuously levels out such advantages, the share in profits becomes dependent on a continuous strive to reducing costs and intensifying labor.

Key-words: Labor intensity, extra surplus value, participation in profits.

JEL Classification: J33.

\section{INTRODUÇÃO}

As formas modernas de remuneração variável, eufemismo para remuneração condicionada ao desempenho, têm se desenvolvido rapidamente no mundo dos negócios porque são formas que se adaptam ao regime de produção com 0 mínimo possível de capital; regime este imposto por condições cada vez mais intensas da concorrência, tanto no plano da concorrência entre capitais quanto no plano da concorrência entre trabalhadores.

A remuneração condicionada, por sua vez, reage sobre o processo e funciona como forma de realizar uma ulterior diminuição das necessidades de capital constante. Desenvolve-se uma relação de mútua sustentação pela qual a produção enxuta exige remuneração variável e por seu turno a remuneração variável produz um maior grau de coesão do capital circulante, ${ }^{1}$ uma maior economia de capital constante, e variável, como se verá a seguir.

* Professor titular da Universidade Federal do Paraná, Departamento de Economia. E-mail: cipolla@ufpr.br. Submetido: M arço, 2005; aceito: Julho, 2006.

${ }^{1}$ Por capital circulante entende-se a soma do capital constante circulante mais o capital variável. 
A produção enxuta implica uma economia de capital variável na medida em que permite a absorção de mais trabalho sem que seja necessária a contratação de mais trabalhadores. A o contrário, a absorção de mais trabal ho vai de mãos dadas com a diminuição do número de trabalhadores. Smith (2000, p. 60) apresenta o seguinte cálculo baseado em pesquisa de Fucini e Fucini (1990). Enquanto 0 trabalhador fordista trabalha 45 segundos a cada minuto, o trabalhador na produção enxuta trabalha 57 segundos a cada minuto. Tomando por base uma diferença de 10 segundos entre os dois sistemas Smith conclui que numa planta de 2000 trabalhadores serão obtidas 2667 horas de trabalho extra a cada turno de 8 horas! N uma semana de trabalho de 40 horas esse diferencial seria equivalente à contratação de 333 trabalhadores adicionais! Esta é a base da participação dos trabal hadores nos lucros das empresas: participação no trabalho adicional por eles próprios fornecido.

E $m$ todas as suas possibilidades essas formas de remuneração se resumem a direitos dos trabalhadores à participação no excedente produzido pelos próprios trabalhadores. Se o salário é o direito à fração do produto que denominamos trabalho necessário, a participação nos ganhos da empresa seria um "direito" à apropriação de uma parcela do trabalho que corresponde ao trabalho excedente? Desse modo a participação em lucros parece ser uma contradição em termos. Se, em condições normais, o pagamento da força de trabalho é igual ao valor da força de trabalho, ao que denominamos de capital variável, como conceber o capital variável enquanto valor que gera excedente e ao mesmo tempo, parcialmente, o nega?

0 mesmo Smith ao considerar as vantagens da remuneração variável formula a seguinte possibilidade: supõe primeiramente um salário igual a x. Posteriormente admite a possibilidade de que o sistema de remuneração variável fixe a parte constante do salário em ? de $\mathrm{x}$. 0 restante? passaria a depender dos lucros da empresa. Se os lucros caem "os salários podem ser cortados até ?" (Smith, 2000 , p. 62). Curiosamente ele não se pergunta de que maneira devemos conceber 0 valor da força da força de trabalho nessas condições. A final o valor da força de trabalho é x ou ?x? O u algum valor intermediário entre $x$ e ?x? A ntes de nos determos sobre essas questões é necessário definir primeiro o que se entende por valor da força de trabalho.

\section{VALOR DA FORÇA DE TRABALHO E SUASFORMAS}

0 valor da força de trabalho entendida enquanto uma mercadoria é aquele quantum que permite reprodução atual e futura da força de trabal ho. Como a força de trabalho futura depende da reprodução natural da população trabalhadora, o valor da força de trabalho deve, por necessidade, englobar uma quantia destinada à manutenção da prole além do necessário à manutenção da força de trabalho atual. Como a manutenção da prole se apoiou historicamente no trabaIho feminino, o valor da força de trabalho deve ser definido como uma quantia 
capaz de adquirir no mercado os meios de subsistência necessários à reprodução da família trabalhadora entendida como a esfera de consumo na qual se preparam os novos elementos daquela classe.

A reprodução normal da força de trabal ho atual implica um pagamento condizente com a intensidade de exploração daquela força. Um pagamento abaixo do condizente com a intensidade de exploração implica que a força de trabalho se reproduz em condições anormais e que deverá ser substituída por novos elementos ainda em fase de formação. $\mathrm{O}$ u inversamente, a força de trabalho atual se reproduz à custa da força de trabal ho futura, caso no qual a força de trabalho futura é formada de modo deficiente.

O salário por tempo nada mais é do que a transformação do valor da força de trabalho em salário/hora. Essa transformação resulta da divisão do valor diário da força de trabalho pelo número de horas de uma jornada de trabalho de duração normal. 0 salário por peça, como veremos a seguir, é também uma forma transformada do valor da força de trabalho na medida em que se origina da divisão do valor diário da força de trabalho pelo número de peças de uma jornada de duração e intensidade normais.

\section{0 salário por peça}

O salário por peça é a forma clássica de pagamento variável da força de trabalho. Por isso a análise das formas de remuneração variável modernas deve começar com o estudo do salário por peça.

O salário por peça é uma forma transformada do valor da força de trabalho e, portanto, deve tomar como dados a duração normal de uma jornada de trabaIho, o grau médio intensidade do trabalho, assim como o número de peças obtido por um trabalhador de habilidade média. A ssim, se o número de peças que se obtém numa jornada de duração normal e de intensidade média é 20 e o valor da força de trabalho é $R \$ 100$, segue que o salário por peça deve ser igual a $R \$ 5$.

Suponhamos que a taxa de mais valia seja de $140 \%$. Isso quer dizer que a quantidade total de trabalho direto realizado na fabricação de cada peça é igual a R\$12:

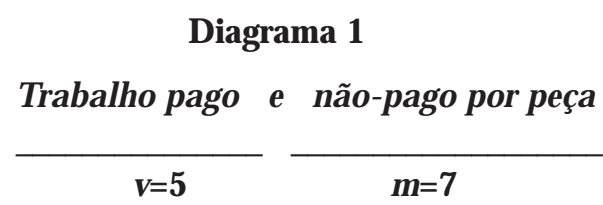

As principais características do salário por peça são enumeradas abaixo de acordo com a apresentação realizada por $\mathrm{M}$ arx no capítulo de mesmo nome do primeiro volume d'O Capital:

1) O salário por peça oferece uma medida exata da intensidade do trabalho;

2) Permite a comparação da intensidade individual com o padrão normal de 
intensidade e, portanto, o mecanismo de avaliação do trabalhador individual e sua eventual substituição;

3) Permite uma redução substancial do trabalho de supervisão já que no sistema de pagamento por peça o trabalhador controla a si mesmo;

4) Com o salário por peça passa a ser do interesse do empregado trabalhar o mais intensamente possível, assim como aumentar a duração da jornada de trabalho;

5) Como resultado o mesmo número de trabalhadores fornecem mais trabaIho e assim a demanda por força de trabalho diminui fazendo baixar os salários;

6) 0 salário por peça abre um espaço de ação para o indivíduo, espaço esse que acirra a concorrência entre os trabalhadores.

O salário diário obtido pela força de trabalho, em regime de pagamento por peça, pode ser definido, uma vez determinado o preço por peça, como sendo:

Salário diário $=$ salário por peça $x$ número de peças produzidas na jornada

À primeira vista a diária aumenta com a intensidade de modo que a remuneração acompanha automaticamente 0 maior desgaste. $M$ as esse não é necessariamente o caso. Q uando o salário por peça representa um pagamento abaixo do valor da força de trabal ho, o trabalhador necessariamente compromete sua reprodução normal ao tentar obter o salário condizente com o valor da força de trabalho. 0 salário por peça, na verdade, torna impossível alcançar uma remuneração de reprodução normal da força de trabalho quando o pagamento pela peça está abaixo do valor que garantiria a remuneração normal com dispêndio normal de energia. Em outras palavras, a intensificação do seu trabalho ou 0 aumento de sua jornada de trabalho não tem compensação, já que a peça é paga abaixo da taxa que corresponde ao valor de uma jornada de intensidade normal.

0 fato de estar impossibilitado de obter o valor da força de trabalho em nada impede que, na tentativa de alcançá-lo, termine por produzir um montante adicional de mais valia como demonstra a tabela abaixo. 0 salário por peça é um meio de obter mais valia absoluta sem que ao trabalhador Ihe seja permitido obter o valor de sua força de trabalho.

Suponhamos que o valor da força de trabalho seja igual a $R \$ 120$ e que o salário corrente seja igual a $R \$ 100$. Se o número de peças de uma jornada normal é igual a 20 , então, o preço por peça é igual a $\mathrm{R} \$ 5$. Para obter o valor nominal de sua força de trabalho a empresa deve produzir 24 peças. Vejamos a tabela.

Tabela 1

Salário por peça e valor da força de trabalho

\begin{tabular}{lcccc}
\hline & $\begin{array}{c}\text { Preço por } \\
\text { Peça }\end{array}$ & $\begin{array}{c}\text { Número de } \\
\text { Peças }\end{array}$ & $\begin{array}{c}\text { Mais-valia } \\
\text { por Peça }\end{array}$ & $\begin{array}{c}\text { Mais-valia } \\
\text { Total }\end{array}$ \\
\hline Salário $=\mathrm{R} \$ 100$ & $\mathrm{R} \$ 5$ & 20 & $\mathrm{R} \$ 7$ & 140 \\
\hline Valor da força de trabalho $=\mathrm{R} \$ 120$ & $\mathrm{R} \$ 5$ & 24 & $\mathrm{R} \$ 7$ & 168 \\
\hline
\end{tabular}

A empresa somente poderá obter o valor nominal da força de trabalho igual a $R \$ 120$ se aumentar a quantidade de trabalho que realiza, seja trabalhando mais 
intensamente, seja trabalhando uma jornada mais longa. Somente uma jornada de intensidade ou duração acima do nível normal permitirá a obtenção do equivalente ao valor nominal da força de trabalho. Isso significa que a obtenção desse valor nominal se dá necessariamente por meio de um maior desgaste da força de trabalho, maior desgaste ao qual não corresponde um pagamento maior. Assim, a obtenção do valor nominal da força de trabalho deixa a trabalhadora com um salário abaixo do valor e o capitalista com $\mathrm{R} \$ 28$ adicionais de mais-valia.

0 que dizer, então, a respeito da remuneração variável ou condicionada? Seria ela igualmente uma forma transformada do valor da força de trabalho, tal como o salário por tempo ou o salário por peça? É o que passamos a explorar a seguir.

\section{Remuneração condicionada e valor da força de trabalho}

Façamos abstração das condições de mercado que não são geradas pelo poder competitivo da própria firma. Consideremos, então, que o desempenho da empresa do qual possam a vir participar os trabalhadores dependa somente do esforço competitivo da própria empresa.

D efinamos pela letra $v$ o valor da força de trabalho, valor que permite a reprodução social da classe trabalhadora de acordo com os padrões normais de consumo daquela classe. 0 bviamente, para que a remuneração total, digamos anual, se ajuste ao valor anual da força de trabalho, é necessário que a parte fi$x a$ seja menor do que $v$. Denominemos a parte fixa do valor da força de trabaIho de $v_{f}$ e a parte variável de $v_{v}$. Suponhamos, seguindo a sugestão de Smith, que $v_{f}=2 / 3$ e $v_{v}=1 / 3$. Considerarmos, para efeitos de ilustração, que 0 valor da força de trabalho seja igual a 900 . Sendo assim, as partes fixa e variável do valor da força de trabalho podem ser representadas como no gráfico abaixo.

\section{Diagrama 2}

$$
v=900
$$

a

$$
v_{f}=600 \quad v_{v}=300
$$

b C

Tomemos de início a primeira parte do diagrama. Se $v-v_{f}$ é igual ao ganho variável, devemos nos perguntar de onde vem essa diferença. Se o segmento ac representa em termos de valor o desempenho normal da força de trabalho, então, para se obter 0 valor $v$ - $v_{f}$ seria necessário que o trabalhador fornecesse uma quantidade de trabalho $\mathrm{ac}^{\prime}>\mathrm{ac}$, tal como representado na parte inferior do diagrama. Isso se deve ao fato de que a origem dos ganhos extras dos quais nos ocupamos não é o aumento da produtividade do trabalho, mas sim a intensificação 
do fluxo do capital circulante, dada uma base técnica, fato que requer necessariamente um aumento do gasto de força de trabalho por unidade de tempo.

Pareceria, à primeira vista, que para obter o equivalente ao valor de sua força de trabalho seria necessário incorrer num desgaste maior do que o normal. Isso teria como efeito o encurtamento da vida útil da mercadoria força de trabalho e, portanto, a necessidade de sua reposição mais cedo por novos elementos de sua classe. Poderíamos alternativamente conceber $v_{f}$ como sendo 0 valor da força de trabalho equivalente à jornada ac enquanto $v$ seria o equivalente ao valor da força de trabalho da jornada ac'. N a prática as duas alternativas são logicamente possíveis e empiricamente viáveis. No entanto, é preciso salientar que a primeira alternativa viola a hipótese de que a remuneração condicionada constitua uma forma transformada do valor da força de trabalho.

Com o desempenho adicional representado pelo segmento $\mathrm{Cc}^{\prime}$, o trabalhador adquire $o$ direito a ganhar um montante extra, qual seja, a diferença $v-v_{f}$. A participação nos resultados da empresa seria medida pela razão $\left(v-v_{f}\right) / c c$ '. Essa razão representa a participação nos lucros e resultados em termos de esforço adicional do trabalhador.

Como esse esforço se consolida em formas que representam economia de capital, seja de capital constante ou de capital variável, o ganho extra da empresa parece resultar de propriedades que advém da administração das coisas. 0 esforço adicional do trabalhador parece originar-se das propriedades do capital de expandir o valor. Desse modo, a participação no seu próprio trabal ho excedente aparece como participação nos lucros e estes como produto da redução do dispêndio de capital.

A demais, aqui o capital administra uma forma de remuneração na qual parte do capital variável não é capital adiantado, nem mesmo capital variável que retorna a fazer as funções de capital variável no seu movimento de circulação de valor enquanto parte do capital circulante. $\mathrm{N}$ a verdade parte do capital variável não está pressuposta como capital já em circulação, mas aparece pela primeira vez na circulação como mais-valia que se realiza como lucros com a venda das mercadorias. ${ }^{2}$ Isso significa que durante $o$ ano os trabal hadores recebem abaixo do valor de sua força de trabalho. $\mathrm{N}$ a verdade, financiam o capital circulante da empresa com uma fração de seu fundo de subsistência anual.

Para o capitalista que $v_{f}<v$ é garantia de que o trabalhador fará das tripas coração para obter a diferença $v-v_{f}$. Assim, quanto piores são as condições de pagamento da força de trabalho mais propensa ela estará para aceitar formas de remuneração que dependam da máxima exerção de trabalho.

Q uando a pressão do desemprego impele o salário para baixo, o aumento da parte condicionada pressupõe a redução da parte fixa. Tal processo estaria

${ }^{2}$ O liveira (2003) observa esse fenômeno mas exagera sua abrangência a ponto de sugerir a partir dele uma eventual superação do próprio conceito de capital variável. 
plenamente de acordo com as condições atuais de exploração da força de trabaIho, condições essas que combinam a pressão "de fora" exercida pela sombra do desemprego que determinaria a parte fixa e a pressão "de dentro" exercida pela crescente tensão do fluxo de produtivo promovida pelos métodos da produção enxuta, que determinaria a parte condicionada.

0 valor da força de trabalho se apresenta como um limite à remuneração dita variável, especialmente em circunstâncias como as atuais, nas quais a pressão sobre a força de trabalho é exercida duplamente pela concorrência entre os trabalhadores e pela concorrência entre os capitais. ${ }^{3}$

\section{Remuneração flexível e intensidade do trabalho}

A remuneração flexível é o suporte subjetivo do fluxo enxuto do capital circulante e, como tal, se apresenta como meio de efetivar a exploração mais intensa da força de trabalho. 0 aumento da intensidade do trabalho, mantido o salário nominal constante, implica um pagamento abaixo do valor. N essas condições, a participação nos ganhos da empresa apenas representa uma compensação pelo maior desgaste da força de trabalho.

A compensação pelo maior desgaste da força de trabalho parece ter sido a causa do famoso "five dollars a day" de H enry Ford. N o seu texto, Ford (1954) argumentava que "é loucura considerar-se o capital e o trabal ho como partidos antagônicos" (p. 96) para dizer em seguida que "os ordenados e salários equivalem a uma espécie de participação nos lucros" (p. 98). "Tais as verdadeiras bases do salário - mera participação de lucros de uma classe de sócios" (p. 99). N a prática o sistema dos 5 dólares por dia foi posto em funcionamento como um complemento do salário, complemento esse condicionado a certas exigências comportamentais (p. 103) por parte dos trabalhadores, de acordo com a fórmula:

$X$ salário + Participação nos lucros $=5$ dólares

"Em 1909", escreve Ford, distribuímos 80 mil dólares com base nos anos de serviço" (p. 101). E completa:

"O pagamento de 5 dólares por dia foi um dos mais belos meios que descobrimos de reduzir o custo, e a elevação a seis dólares outro mais belo ainda" (idem, p. 116).

É importante observar que uma das razões subjacentes ao aumento dos salários era a altíssima rotatividade da força de trabalho, constrangida a abando-

\footnotetext{
${ }^{3}$ Tadaieski (2003) apresenta dados relativos ao salário médio e valor anual da participação nos lucros e resultados para as três montadoras instaladas no Paraná: a Volkswagen-Audi, a Volvo e a Renault. Enquanto o salário médio se situa entre $R \$ 880$ e $R \$ 1250$ a gratificação anual se situa entre um e 2,5 salários mensais. É possível que, cotejados contra o custo de reprodução da força de trabaIho na Grande Curitiba, nem mesmo os trabalhadores da elite industrial obtenham o equivalente ao valor de sua força de trabalho.
} 
nar a empresa devido às condições estafantes de trabalho. De fato, o aumento de salários logrou diminuir drasticamente a rotatividade (p. 104).

\section{Remuneração flexível, economia de capital variável e intensidade do trabalho}

Existem dois âmbitos em que se logra economizar capital variável. Em geral se enfatiza somente o fato de que por não se incorporarem ao salário todas as formas de bônus e prêmios economizam encargos trabalhistas, fato que reduz a folha salarial relativamente à produção realizada. $M$ as esse é apenas um aspecto.

A specto não menos importante é a economia de capital variável advinda do aumento da intensidade do trabal ho, aumento esse inextricavel mente ligado à participação dos trabalhadores nos resultados das empresas. 0 aumento da intensidade representa um maior dispêndio de trabalho. $0 \mathrm{~s}$ trabalhadores fornecem mais trabalho à empresa sem que esta precise contratar mais força de trabaIho. $\mathrm{N}$ a verdade há uma dupla redução de encargos: os encargos driblados pelos pagamentos "por fora" do sistema trabal hista vigente e os encargos relativos aos trabalhadores adicionais que seriam necessários caso o aumento da quantidade de trabalho não se desse por via do aumento da intensidade, mas sim por via do aumento do número de indivíduos empregados.

Como forma transformada do valor da força de trabalho, o salário condicionado não pode guardar relação com a variação dos lucros das empresas, exceto enquanto média de compensações que ao longo do tempo se resumissem ao valor da força de trabalho.

D e fato, os dados mostram que a remuneração condicionada está ligada a indicadores de desempenho individual ou coletivo, desempenho esse sempre relacionado com formas de aumento da taxa de trabalho útil $(c \rightarrow c)$ ou de aumento da taxa de trabalho abstrato $(v \rightarrow L) \cdot{ }^{4} \mathrm{~A}$ relação entre sistema de pagamentos atrelados à performance da empresa e 0 aumento da intensidade do trabalho podem ser confirmados pelo tipo de acordo predominante definido nas cláusulas de participação nos lucros e resultados, as conhecidas PL Rs. Como podemos confirmar pela tabela a seguir os acordos predominantes estão sempre ligados a formas de envolvimento da força de trabalho com os interesses mercantis da empresa.

\footnotetext{
${ }^{4}$ Trabalho útil ou concreto se refere ao trabalho enquanto produtor de valores de uso. Trabalho abstrato se refere ao trabalho enquanto produtor de valor. Do ponto de vista do trabalho corrente podemos dizer que na sua dimensão útil ele conserva o valor dos meios de produção enquanto na sua dimensão abstrata ele cria valor adicional.
} 
Tabela 2

Distribuição dos 1659 acordos entre as modalidades de remuneração flexível

\begin{tabular}{lcc}
\hline Modalidades & № & $\%$ \\
\hline Participação nos Lucros (PL) & 63 & 3,8 \\
Participação nos Resultados (PR) & 901 & 54,3 \\
Participação Mista (PL\&R) & 216 & 13,0 \\
Participação Independente (PI) & 478 & 28,8 \\
\hline Total & 1659 & $100 \%$ \\
\hline
\end{tabular}

Fonte: Um Balanço da Participação dos Trabalhadores nos Lucros e Resultados das Empresas: 1996-1999. Pesquisa DIEESE, no 16, J aneiro de 2000, p. 63, tabela 30.

É interessante observar a predominância da participação nos resultados no conjunto dos acordos realizados. Ainda mais clara fica a conexão entre remuneração flexível e intensidade do trabalho quando se observa a natureza específica dos acordos quanto ao tipo de indicador utilizado para aferição do desempenho.

Tabela 3

Indicadores utilizados nos Acordos Coletivos. Brasil 1996-1999

\begin{tabular}{lccccc}
\hline Tipos de indicadores & 1996 & 1997 & 1998 & 1999 & Total \\
\hline Indicadores Comportamentais & 25,2 & 22,8 & 31,3 & 29,7 & 26,7 \\
Produtividade & 10,5 & 9,6 & 11,1 & 9,2 & 10,1 \\
Produção e vendas & 12,9 & 15,2 & 13,2 & 17,1 & 14,6 \\
Redução de custos/Desperdício & 5,0 & 6,3 & 7,2 & 8,8 & 6,7 \\
Rentabilidade/Lucro & 5,5 & 6,1 & 6,5 & 7,3 & 6,3 \\
Qualidade & 23,6 & 19,6 & 24,9 & 21,8 & 22,1 \\
\hline Total & 100,0 & 100,0 & 100,0 & 100,0 & 100,0 \\
\hline
\end{tabular}

Fonte: Um Balanço da Participação dos Trabalhadores nos Lucros e Resultados das Empresas: 1996-1999. Pesquisa DIEESE, № 16, J aneiro de 2000, p. 63, tabela 30.

Algumas observações sobre os itens Comportamentais e de $Q$ ualidade se fazem necessárias. $\mathrm{N}$ o primeiro sobressai o absenteísmo como mecanismo de controle para a distribuição de prêmios. A redução do absenteísmo é fator chave da produção enxuta já que esta se baseia no enxugamento de capital variável. N os indicadores de qualidade três deles têm implicação na economia de capital constante e no aumento da taxa de trabalho útil conjuntamente, quais sejam, a redução de refugo; a conformidade à norma de qualidade e a redução de re-trabalho. 0 aumento da taxa de trabalho útil implica necessariamente uma redução do custo de capital constante e variável por unidade de produto. 
É importante observar que o item produtividade refere-se ao aumento de produção por trabalhador. O u seja, se inclui o aumento da intensidade como aumento de produtividade. ${ }^{5}$

O s dados apresentados mostram que a remuneração condicionada não depende do desempenho da empresa em abstrato e, portanto, não pode ser caracterizada como participação nos lucros. Trata-se, outrossim, de remuneração condicionada ao desempenho do próprio trabalhador como atestam os indicadores individualizados que servem para aferir a contribuição do empregado para a eficiência da firma.

O s limites de intensificação do trabalho que se podem impor à força de trabalho encontram na administração fabril e nos seus teóricos da administração formas engenhosas de flexibilização. O ishi (1995, p. 106), por exemplo, apresenta a definição de densidade de trabalho como sendo a razão da movimentação para o trabalho produtivo/movimentação do trabalho não produtivo. Claramente, a densidade de trabalho pode aumentar sem aumento da intensidade do trabalho "deslocando-se" a movimentação do trabalho não produtivo para trabaIho produtivo! ${ }^{6}$

\section{TAXA DE LUCRO E NATUREZA DO CAPITAL}

O capital, sendo valor em processo de valorização tem em sua natureza a tendência a reduzir continuamente $o$ estoque de capital para um determinado fluxo de produto. Isso pode ser verificado facilmente quando calculamos a taxa de lucro considerando apenas o capital constante circulante. $N$ esse caso, a taxa de lucro se reduz à margem de lucro. Consideremos $\mathrm{k}$ como o custo unitário de capital circulante (constante e variável), $\mathrm{w}_{\mathrm{m}} \mathrm{o}$ valor de mercado do produto da indústria específica, entendido por indústria a soma dos produtores de uma mesma espécie de mercadoria, cigarros, por exemplo.

Se considerarmos, então, somente o capital circulante, a diminuição do capital adiantado, neste caso o custo unitário k tem o duplo efeito de aumentar o lucro unitário e diminuir o capital adiantado. A taxa de lucro aumenta.

\footnotetext{
${ }^{5} \mathrm{~A}$ relação entre remuneração flexível e intensidade do trabalho pode ser também atestada pelas referências dos próprios administradores e empresários a respeito: "A inserção da remuneração variável 'muda a cabeça do trabalhador'. Eles passam a acompanhar os resultados da companhia e a trabal harem motivados" (Superintendente de recursos humanos da Credicard, Valor, 26-07-04, p. A5). "A companhia vê com bons olhos o sistema para motivar os funcionários a buscar melhores resultados" (Gerente administrativo da Petroquímica Triunfo, idem). "O programa de participação nos resultados gera um ambiente 'sadio' e faz com que os dois mil funcionários 'vistam a camisa' da empresa" (Diretor presidente da Kepler Weber, idem, p. A6).

${ }^{6}$ É importante esclarecer que a noção de trabalho produtivo de 0 ishi se relaciona ao trabalho diretamente vinculado à fabricação do produto, excluindo, portanto, o transporte de materiais no interior da fábrica. Para M arx, trabalho produtivo é trabalho produtor de mais valia e inclui não só o transporte de materiais no interior da fábrica como também o trabalho realizado na área de logística.
} 
No entanto, para o capital toda a valorização quantitativa é limitada face ao seu desígnio qualitativo de expansão absoluta. A tendência do capital é, pois, reduzir o capital adiantado a zero.?

Esse desígnio de expansão absoluta encontra limites tanto na própria natureza interna do capital, isto é, nas fases do circuito pelas quais deve passar no seu processo de expansão do valor, quanto na sua natureza externa, isto é, sua existência enquanto multiplicidade de capitais em concorrência uns contra os outros. Vejamos.

\section{0 limite interno: as fases do circuito como barreira}

O capital, no seu circuito de valorização, se fixa temporariamente em cada uma das fases que compõem o circuito: a compra, a produção; a venda:

$$
D-M_{(M P)}^{(F T)} \ldots . . P \ldots . . . M^{\prime}-D^{\prime}
$$

As fases circulatórias de compra ( $D$ - M ) e venda ( $\left.M{ }^{\prime}-D^{\prime}\right)$ do circuito não adicionam valor ao capital, pelo contrário, funcionam no sentido inverso de desvalorizá-lo já que empatam capital sem aumentar a mais-valia. Por outro lado, a fixação temporária do capital em cada uma de suas fases atrasa pro rata a velocidade do processo de valorização e impede que o capital volte a funcionar como extrator de mais-valia.

\section{O limite externo e a lei fundamental da concorrência capitalista}

A existência do capital enquanto múltiplos capitais implica que cada capital individual encontra nos outros capitais do seu ramo uma limitação à expansão do valor. 0 meio fundamental de abrir caminho é a redução do custo e a conquista de maiores parcelas de mercado.

A lei fundamental da concorrência capitalista pode ser resumida da seguinte maneira: enquanto o custo $k=c+v$ é um fenômeno relativo ao capital individual, o valor é um fenômeno relativo ao trabalho coletivo de uma determinada indústria. O s capitais que logram diminuir k obtêm ganhos extras, fenômeno que M arx denominou de mais-valia extraordinária. Se supusermos que o capital individual venda a sua mercadoria ao valor de mercado, $w_{m}$, então os lucros serão determinados como:

$$
\text { lucro }=w_{m}-k
$$

\footnotetext{
7 O hno assim se expressa: "Just-in-time significa que, em um processo de fluxo, as partes corretas necessárias à montagem alcançam a linha de montagem no momento em que são necessárias e somente na quantidade necessária. Uma empresa que estabeleça esse fluxo integralmente pode chegar ao estoque zero... Do ponto de vista da gestão da produção, esse é um estado ideal" (O hno, 1997, p.26).
} 
O capital individual dispõe de duas variáveis que determinam seu lucro: o custo individual e o preço de venda individual que pode ser inferior ao valor de mercado.

Do ponto de vista do capital individual, os ganhos extras advêm da diminuição dos custos unitários k. Com a diminuição dos custos unitários aumenta a diferença entre valor de mercado e valor individual. 0 aumento dos lucros resulta dessa diferença.

Q uando o capital adiantado, por unidade de produto, é igual ao custo k, a diminuição de $\mathrm{k}$ afeta a taxa de lucro por duas vias: diminui o custo unitário, k, e diminui o estoque de capital, $\mathrm{k} \cdot \mathrm{Q}$, onde $\mathrm{Q}$ é a quantidade de produto:

$$
\text { taxa.de.lucro }=\frac{w_{m}-k}{k}
$$

Todo capital tem como objetivo intrínseco fazer o capital adiantado $C=c+v$ se aproximar cada vez mais do capital que compõe o custo da mercadoria e que retorna a cada período de rotação do capital circulante.

A participação nos lucros está ligada à diminuição dos custos de capital variável (v) e constante (c), na medida em que uma força de trabalho de magnitude dada logra transformar um volume maior de materiais sem o auxílio de capital fixo adicional. A maior quantidade de trabalho se transubstancia numa quantidade maior de valores de uso e de mais-valia.

O ra, o valor maior realizado, mantida a taxa salarial constante, corresponde a uma redistribuição do valor novo gerado pelo trabalho entre parte paga e parte não paga. No diagrama que segue supomos que a diminuição do número de trabalhadores é a causa do aumento da intensidade do trabal ho. ${ }^{8}$ Por isso mantemos a quantidade total de trabalho constante, fato ilustrado pelos segmentos de reta de igual tamanho antes e depois da redução de custos:

\section{Diagrama 3}

Antes_ $\frac{v}{\mathrm{v}} \frac{\mathrm{m}}{\mathrm{m}}$

É essa redistribuição ex-ante do novo valor gerado pelo trabal ho que permite com que o trabalhador participe, post festum, no resultado da economia de trabalho e, portanto, no aumento do trabalho grátis que ele próprio propiciou.

Esse aumento dos lucros não advém de uma redução do valor da força de trabalho, mas sim da intensificação do trabalho implícita na produção enxuta

\footnotetext{
${ }^{8}$ Tanto a "autonomação", dispositivo de parada automático da máquina, quanto a organização do trabalho em equipe, constituem formas de aumento da intensidade do trabalho.
} 
que é, por definição, a produção com o mínimo de estoques e, portanto, com o mínimo de capital, tanto constante circulante quanto variável. Trata-se aqui de economia de capital variável a um dado valor da força de trabalho e não como resultado da redução do seu valor.

A quantidade de trabalho a mais extraída de cada unidade de força de trabalho se traduz num maior número de valores de uso por trabal hador. $\mathrm{N}$ o entanto, esse trabalho adicional só é remunerado ex-post. Enquanto no trabalho por peça o trabalhador é remunerado pela produção antes que essa se realize em dinheiro para o capital, nas formas de remuneração flexível o aumento da eficiência do trabalho, medido em termos de lucros, requer a realização prévia do produto em dinheiro. Como tal, a remuneração flexível depende sempre da contabilidade capitalista e, como tal, está sempre submetida a subterfúgios que escapam do controle dos trabalhadores. ${ }^{9}$

É claro que no contexto de redução contínua de custos esse processo não pode depender da mecanização, mas deve, outrossim, basear-se na contínua economia de capital. Isso é o que se conhece sob o nome de Kaizen.

Essa economia de capital só é possível através da instauração de processos produtivos cada vez mais enxutos, fato que requer uma crescente diligência no trabalho. A diminuição dos custos unitários que daí advém é precisamente o modo de obtenção de mais-valia extraordinária, processo esse que M arx denominou de lei fundamental da concorrência capitalista.

Vejamos mais de perto como se entrelaçam remuneração flexível, intensidade do trabalho e ganhos extraordinários. Para isso apresentaremos primeiramente a lei fundamental em termos de capital variável para depois introduzirmos o capital constante circulante.

\section{M odelo de capital variável: só v}

Consideremos primeiramente a situação na qual a mais-valia extraordinária advenha do aumento da intensidade do trabalho. Enquanto a massa salarial se mantém constante, a quantidade total de trabalho fornecida pelo trabalhador ao capitalista aumenta. Devemos supor, na ausência de qualquer aumento da produtividade do trabalho, que o aumento do número de produtos produzidos seja resultante da maior massa de trabalho obtida pela via do aumento da intensidade do trabalho. Com apenas capital variável, o número adicional de produtos é resultado do trabalho adicional de modo que a quantidade de trabalho por produto continua a mesma.

Enquanto a quantidade total de trabalho se mantém constante, o mesmo não ocorre com o custo salarial unitário. Com a massa salarial constante o custo sa-

\footnotetext{
${ }^{9}$ Diferentemente da remuneração por peça na qual a trapaça se baseia no fato de que é em última análise 0 capitalista que decide quais peças atingem o padrão de qualidade e, portanto, quais peças serão remuneradas.
} 
larial unitário decresce na proporção em que aumenta a quantidade de valores de uso produzidos. Este é um resultado el ementar, mas importante: o aumento da intensidade do trabalho reduz o custo salarial por unidade de produto. A baixo representamos esse resultado por meio de duas retas, uma representando 0 valor de mercado e a outra o valor individual das mercadorias do capital que logra intensificar o trabalho acima da média:

\section{Diagrama 4}

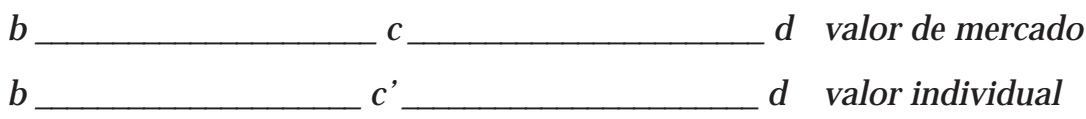

0 valor unitário é igual já que a maior quantidade de produtos foi gerada por uma quantidade equivalentemente maior de trabalho. Porém, o custo salarial, segmento $b c^{\prime}$, é menor, pois a mesma massa salarial se divide por um maior número de produtos. A umenta para o capital individual a proporção não-paga do valor do produto, o segmento $\mathrm{cd}$.

$\mathrm{N}$ essas condições o capital individual pode sacrificar parte do trabalho excedente fornecido pelo trabalhador e assim diminuir o valor do seu produto abaixo do valor de mercado.

\section{Diagrama 5}

b C d valor de mercado

b $c^{\prime}$ $d^{\prime}$ d valor individual

O segmento c'c representa o aumento da mais-valia pela via absoluta - por unidade de produto - já que resulta de um aumento da quantidade de trabalho e não de uma redução de v. 0 capitalista pode renunciar a uma parte do trabaIho não pago desde que essa renúncia não exceda a dimensão $c^{\prime} c$. Assim fazendo o capitalista individual está repassando grátis ao comprador parte do trabalho que Ihe foi fornecido gratuitamente pelo trabalhador. Suponhamos que a redução seja de dimensão d'd e que obedeça a desigualdade

$c^{\prime} c>d^{\prime} d$

$\mathrm{N}$ esse caso cada unidade de produto gera para o capitalista individual um ganho extraordinário

$$
g x=c^{\prime} c-d^{\prime} d>0
$$

Esse ganho extraordinário unitário multiplicado pelo volume total produzido é igual ao ganho extraordinário advindo da intensificação do trabalho. Esse ganho extraordinário é o fundamento da participação nos lucros. Isso significa que os trabal hadores "participam" nos ganhos que advém de sua maior explora- 
ção pelo capital: os trabalhadores obtêm uma pequena fração da mais-valia extra que o seu trabalho mais intenso permite ao capitalista obter.

\section{M odelo de capital circulante: v e c}

Em princípio a introdução de capital constante não altera nada, pois a quantidade de materiais transformados por unidade de produto se mantém igual no período de trabalho mais intenso. 0 montante de depreciação do capital fixo por unidade de produto resulta de duas forças contrárias: a mais rápida depreciação que advém do uso mais intenso e o maior número de produtos pelos quais se divide o valor da máquina. Se supusermos que essas duas forças se compensem, então, o custo individual da mercadoria diminui exclusivamente em virtude da redução do custo salarial unitário.

$\mathrm{N}$ a verdade, a aceleração do circuito acarreta também uma diminuição dos custos unitários de capital constante, tanto fixo quanto circulante. 0 diagrama a seguir representa esses resultados.

\section{Diagrama 6}

a

b

C

$d v_{m}$

a

b

$c^{\prime}$

$d v_{i}$

O segmento aa' corresponde ao montante de economia de capital constante. Essa economia inclui todos os elementos afetados pelo aumento da velocidade de rotação do capital circulante. Esses elementos são: a diminuição do capital produtivo latente e os custos associados à sua manutenção; a diminuição do desperdício devido à fabricação defeituosa; diminuição do capital variável relativo às atividades de controle de qualidade; menores custos de conservação da mercadoria em estado de oferta. 0 segmento $c^{\prime} c$ corresponde à redução do custo salarial unitário, redução esta analisada no item anterior.

A margem potencial de lucro é agora maior do que no caso analisado anteriormente quando não considerávamos o capital constante. 0 capital individual que logra diminuir custos através da aceleração do circuito pode igualmente diminuir seu preço de venda e aumentar sua massa de lucro através de um volume maior de vendas.

Desde que a diminuição do preço, d'd, seja menor do que a redução de custos, teremos um aumento da margem de lucro unitário, ou, nos termos de M arx, mais-valia extraordinária resultante da diferença entre o preço de venda e o valor individual. A condição para que esse resultado ocorra é, então:

$$
d^{\prime} d<\left(a a^{\prime}+c^{\prime} c\right)
$$

A aceleração do circuito provoca um enxugamento de pessoal que reduz 0 número de pessoas empregadas. A redução do custo de capital variável por uni- 
dade de produto tem, portanto, duas fontes: menor estoque de capital variável e maior fluxo de produto. Considerando $\mathrm{N}$ como sendo o número de trabalhadores e Q o fluxo de produto temos o custo salarial unitário determinado pelo quociente

$$
\frac{N . v}{Q}
$$

Como dissemos, $\mathrm{N}$ diminui e $\mathrm{Q}$ aumenta. A redução do custo salarial unitário tem, portanto, duas fontes.

Como vimos anteriormente, a redução de custos que propicia a nova divisão mais vantajosa entre mais-valia e salários é possibilitada pela aceleração do circuito do capital circulante, aceleração essa que, como vimos no capítulo anterior, vai de tango com a intensificação do trabalho. É essa redução de custo que possibilita o aumento da margem de lucro. É esse aumento da margem de lucro que abre espaço para a participação nos lucros. Assim, a participação nos lucros depende da redução de custos unitários.

No entanto, toda redução de custo obtida por um capital individual é, mais cedo ou mais tarde, reproduzida pelos outros capitais. A base para a participação nos lucros é, pois, constantemente erodida pela concorrência. A condição de sua sustentação continuada depende de um processo de contínua redução de custos. Daí o kaizen.

A melhora contínua que procura mobilizar a participação e o envolvimento dos trabal hadores na procura de diferenciais de custos quando ocorre simultaneamente em todos os capitais elimina a possibilidade do lucro extraordinário. A participação nos lucros, no que diz respeito aos lucros extraordinários, é uma impossibilidade quando se pensa o conjunto das empresas concorrentes agindo de forma similar.

A participação nos lucros como expressão da concorrência só pode se dar para os capitais que se adiantam no processo competitivo. A tentativa de todos os capitais de fazê-lo cancela a possibilidade de participação nos lucros, pois as vantagens individuais se anulam. 0 saldo desse processo é a redução dos preços que advém da redução dos custos. À medida que os preços se reduzem cai o valor da força de trabalho. A ssim, o processo de participação em ganhos das empresas deixa no seu rastro 0 aumento da taxa de mais-valia.

\section{CONCLUSÕES}

A participação nos ganhos das empresas se resume à participação dos trabaIhadores a uma fração da mais-valia extraordinária obtida pela via absoluta da intensificação do trabalho. Como a concorrência anula essas vantagens, a participação dos trabalhadores nos ganhos das empresas encontra limites na própria possibilidade de aumento da intensidade do trabalho.

Como a anulação contínua das vantagens de custo pela concorrência é um 
pressuposto da estratégia das empresas, a ação recíproca entre elas cria uma febre pela contínua redução de custos, o kaisen. 0 capital se utiliza desse ambiente competitivo para manter a força de trabal ho continuamente mobilizada no limite do stress, impedindo assim uma queda no nível do comprometimento com a produção enxuta.

Como expressão da lei fundamental da concorrência capitalista de redução dos custos, k, e conseqüente aumento da margem de lucro, a participação nos resultados põe em moto um regime de contínua pressão para o envolvimento dos trabalhadores nos interesses da empresa já que os resultados são cancelados periodicamente pelo catching up dos concorrentes. Essa pressão contínua encontra seus limites no grau de intensificação do trabal ho que pode suportar a força de trabalho. A participação dos trabalhadores nos ganhos das empresas é limitada pela própria capacidade da força de trabalho de produzir mais-valia pela via absoluta da intensificação do trabalho.

Finalmente caberia acrescentar que, em condições de acentuado desemprego, condições nas quais o salário é incapaz de subir acima do valor da força de trabalho, a remuneração condicionada encontra limites no próprio salário de reprodução normal da força de trabalho, ou seja, o seu valor.

\section{REFERÊN CIAS BIBLIO GRÁFICAS}

DIEESE. Um balanço da participação dos trabalhadores nos lucros e resultados das Empresas: 19961999. São Paulo: Pesquisa DIEESE, no. 16.

Ford, H enry. M inha Vida e M inha O bra in O s Princípios da Prosperidade. Rio de Janeiro: Editora Brand Ltda., 1954.

Fucini, J oseph e S. Fucini. Working for the Japanese: Inside M azda's A merican A uto Plant. N ew York: The Free Press, 1990.

M arx, Karl. Capital. N ew York: International Publishers, 1967.

O hno, Taiichi. O Sistema Toyota de Produção: A lém da Produção em Larga Escala. Porto Alegre: Bookman Companhia Editora, 1997.

O ishi, M ichitoshi. Tips: Técnicas I ntegradas na Produção e Serviços. São Paulo: Livraria Pioneira Editora, 1995.

O liveira, Francisco. Crítica da R azão D ualista - 0 O rnitorrinco. São Paulo: Boitempo, 2003.

Smith, Tony. Technology and Capital in the A ge of Lean Production. N ew York: State University of $\mathrm{N}$ ew York Press, 2000.

Tadaieski, Lizandra. A Influência dos Programas de Participação de Lucros e R esultados (PLR) na Remuneração dos M etalúrgicos das M ontadoras Instaladas no Paraná no Período de 2000, 2001 e 2003. Curso de Especialização em E conomia do Trabalho, D epartamento de Economia-Centro de Pesquisas Econômicas, Universidade Federal do Paraná, 2003.

Valor E conômico. "Participação nos lucros aumenta em diferentes categorias" , 26 de julho de 2004, p. A5.

Valor E conômico. "M ais empresas vinculam bônus ao alcance de metas de produção", 26 de julho de 2004, p. A6. 